\title{
Comparative study of a novel selective urate reabsorption inhibitor "dotinurad" among patient groups with different stages of renal dysfunction
}

\author{
Toshinari Takahashi ${ }^{1} \cdot$ Takanobu Beppu $^{2} \cdot$ Yuji Hidaka $^{3} \cdot$ Tatsuo Hosoya $^{4}$
}

Received: 31 March 2021 / Accepted: 15 July 2021 / Published online: 30 July 2021

(c) The Author(s) 2021

\begin{abstract}
Background Dotinurad is a selective urate reabsorption inhibitor (SURI), which selectively inhibits URAT1 to lower serum uric acid levels in patients with hyperuricemia. Herein, the effects of dotinurad were compared among patient groups with different stages of renal dysfunction.

Methods Patient data from four clinical trials were pooled and divided into four groups according to the stage of renal dysfunction to compare the effects of dotinurad at different stages. The grouping (stages G1-G3b) was based on the estimated glomerular filtration rate (eGFR) of the patients. In addition, patient data from a long-term study (34 or 58 weeks) were evaluated in the same manner.

Results In the pooled analysis, the percentage of patients achieving a serum uric acid level of $\leq 6.0 \mathrm{mg} / \mathrm{dL}$ was $64.7-100.0 \%$ at a dose of 2 or $4 \mathrm{mg}$. In the long-term analysis, the percentage of patients achieving a serum uric acid level of $\leq 6.0 \mathrm{mg} / \mathrm{dL}$ was $60.0-100.0 \%$ at a dose of 2 or $4 \mathrm{mg}$. Although the outcomes in stage G3b were worse due to higher baseline serum uric acid levels, satisfactory outcomes were observed in all stages. Even in stages G3a and G3b, when renal function declined, the eGFR remained constant throughout the dose period.

Conclusion The efficacy of dotinurad was confirmed in hyperuricemic patients with normal renal function (stage G1) and mild to moderate renal dysfunction (stage G2-G3b). Dotinurad was found to be effective in the treatment of hyperuricemia in patients with mild to moderate renal dysfunction.
\end{abstract}

Keywords Hyperuricemia $\cdot$ Chronic kidney disease $\cdot$ Selective urate reabsorption inhibitor · URAT1 inhibitor · Dotinurad

\section{Introduction}

Hyperuricemia results in urate deposition diseases, such as urolithiasis and gouty arthritis. In addition, recent studies have shown that hyperuricemia is closely related to lifestyle

Toshinari Takahashi

toshinari.takahashi@mochida.co.jp

1 Medical Affairs Department, Mochida Pharmaceutical Co., Ltd, 1-22 Yotsuya, Shinjuku City, Tokyo 160-0004, Japan

2 Medical Affairs Department, Fuji Yakuhin Co., Ltd, 9F Kanda Square Building, 2-2-1 Kandanishiki-cho, Chiyoda City, Tokyo 101-8189, Japan

3 Akasaka Central Clinic, 3-21-16 Akasaka, Minato City, Tokyo 107-0052, Japan

4 Jikei University School of Medicine, 3-25-8 Nishi-Shimbashi, Minato City, Tokyo 105-8461, Japan diseases, such as chronic kidney disease, hypertension, and diabetes mellitus [1-3]. Coupled with the aging of the population and westernization of lifestyle, the number of these lifestyle diseases has been increasing. Because of this trend, it is expected that the number of patients with hyperuricemia will continue to increase in the coming decades [4].

According to the latest Japanese guidelines for the management of hyperuricemia and gout [1], uric acid production inhibitors are recommended for patients with chronic kidney disease (CKD; stage 4 or higher). However, in other patient populations, it was suggested that no difference in outcomes would be expected if either uric acid production inhibitors or uricosuric drugs were selected. Although many Japanese patients with hyperuricemia have the characteristic of underexcretion, uricosuric drugs are not often used to treat such patients [5]. Lesinurad, a selective urate reabsorption inhibitor (SURI), which is a URAT1 inhibitor that does not affect other urate transporters, such as OAT1 and OAT3, 
has recently been approved in the United States and Europe [6]. Lesinurad is indicated in combination with an XOI for patients with gout who failed to achieve the target serum uric acid level due to serious, acute kidney injury, which was observed with high-dose lesinurad monotherapy in a clinical study [7].

Although "underexcretion type" hyperuricemia is observed in many patients with renal impairment, uricosuric drugs (including lesinurad) have not been used because of safety concerns. Thus, there is a need for safer drugs with sufficient serum uric acid-lowering effects [5]. Dotinurad is a novel SURI for the treatment of hyperuricemia. It was developed to improve the safety problems associated with conventional uricosuric drugs while maintaining a strong serum uric acid-lowering effect. Previous clinical trials have confirmed the non-inferiority of dotinurad to benzbromarone [8] and febuxostat [9]. In addition, the safety and efficacy of long-term use have already been evaluated [10]. In Japan, as mentioned above, the number of hyperuricemic patients with renal impairment is expected to increase due to lifestyle diseases [11]. In this situation, it is essential to evaluate the safety of dotinurad in patients with renal impairment. In this study, the safety and efficacy of dotinurad, including its long-term use, were examined in patients with renal impairment based on the analyses of pooled clinical data from several trials conducted to date.

\section{Methods}

\section{Data set}

Clinical data of patients who were administered dotinurad were extracted from four clinical trials and gathered as a data set. The details are as follows: 60 cases were extracted from the phase IIa trial (NCT02344862) [12], 160 from the phase IIb trial (NCT02416167) [13], 102 from the non-inferiority trial to benzbromarone (NCT03100318) [8], and 99 from the non-inferiority trial to febuxostat (NCT03372200) [9].
For long-term evaluation, 326 cases from a long-term trial (NCT03006445) [10] were used as the data set. The inclusion and exclusion criteria for the study subjects were the same in all trials in which patients with "underexcretion type" hyperuricemia were recruited. In four clinical trials, dotinurad was initiated at a dose of $0.25 \mathrm{mg}$ or $0.5 \mathrm{mg}$ daily and was gradually increased to the maintenance dose $(0.5$, $1,2,4 \mathrm{mg}$ ). In a long-term study, dotinurad was initiated at a dose of $0.5 \mathrm{mg}$ daily and increased up to 2 or $4 \mathrm{mg}$. The treatment periods were 8-14 weeks in the four trials and 34 or 58 weeks in the long-term trials. The details of each trial are summarized in Table 1.

In the pooled analysis, 421 cases were divided into four groups according to eGFR, which is a standard indicator of the stage of renal dysfunction. Grouping was as follows: stage G1, eGFR $\geq 90 \mathrm{~mL} / \mathrm{min} / 1.73 \mathrm{~m}^{2}$; stage $\mathrm{G} 2,60 \mathrm{~mL} /$ $\min / 1.73 \mathrm{~m}^{2} \leq \mathrm{eGFR}<90 \mathrm{~mL} / \mathrm{min} / 1.73 \mathrm{~m}^{2}$; stage G3a, $45 \mathrm{~mL} / \mathrm{min} / 1.73 \mathrm{~m}^{2} \leq \mathrm{eGFR}<60 \mathrm{~mL} / \mathrm{min} / 1.73 \mathrm{~m}^{2}$; and stage G3b, $30 \mathrm{~mL} / \mathrm{min} / 1.73 \mathrm{~m}^{2} \leq \mathrm{eGFR}<45 \mathrm{~mL} / \mathrm{min} / 1.73 \mathrm{~m}^{2}$. This grouping was performed in reference to the Japanese guidelines for the treatment of CKD [14]. In each stage, patient data were further divided into dose sub-groups (0.5-4 mg daily), and outcomes were examined in each sub-group. In the long-term analysis, 7 out of 326 patients were excluded, because the maintenance dose had not been administered for the prescribed duration, and the other 319 cases were extracted and divided into four groups in the same manner as described above (stages G1-G3b), and were evaluated in the 2 or $4 \mathrm{mg}$ dose sub-group.

\section{Study endpoints}

In the pooled analysis, the percentage change in serum uric acid level from the baseline, and percentage of patients achieving a serum uric acid level of $\leq 6.0 \mathrm{mg} / \mathrm{dL}$ at the end of the dose period were examined in stages G1-G3b. In the long-term analysis, the incidence of adverse events (AEs) during the dose period, change in eGFR, percentage change in serum uric acid level from the baseline, and percentage of patients achieving a

Table 1 Clinical trials of dotinurad

\begin{tabular}{|c|c|c|c|c|}
\hline Clinical trial gov ID & Study objectives & Dotinurad dose (day) & Dosing period & No. of total patients \\
\hline NCT02344862 & $\begin{array}{l}\text { Dose response, optimal dose and safety (phase } \\
\text { 2a) }\end{array}$ & $\begin{array}{l}0.25 \rightarrow 0.5 \rightarrow 1,2,4 \mathrm{mg} \\
\text { placebo }\end{array}$ & 8 weeks & 80 \\
\hline NCT02416167 & $\begin{array}{l}\text { Dose response, optimal dose and safety (phase } \\
2 \mathrm{~b} \text { ) }\end{array}$ & $\begin{array}{l}0.25 \rightarrow 0.5 \rightarrow 0.5,1,2,4 \mathrm{mg} \\
\text { placebo }\end{array}$ & 12 weeks & 199 \\
\hline NCT03100318 & $\begin{array}{l}\text { Non-inferiority test to benzbromarone and } \\
\text { evaluation of safety }\end{array}$ & $\begin{array}{l}0.5 \rightarrow 1 \rightarrow 2 \mathrm{mg} \\
\text { benzbromarone } 25 \rightarrow 50 \rightarrow 50 \mathrm{mg}\end{array}$ & 14 weeks & $\begin{array}{l}\text { Dotinurad: } 102 \\
\text { benzbromarone: } 98\end{array}$ \\
\hline NCT03372200 & $\begin{array}{l}\text { Non-inferiority test to febuxostat and evaluation } \\
\text { of safety }\end{array}$ & $\begin{array}{l}0.5 \rightarrow 1 \rightarrow 2 \mathrm{mg} \\
\text { febuxostat } 10 \rightarrow 20 \rightarrow 40 \mathrm{mg}\end{array}$ & 14 weeks & $\begin{array}{l}\text { Dotinurad: } 99 \\
\text { febuxostat: } 100\end{array}$ \\
\hline NCT03006445 & Long-term efficacy and safety & $\begin{array}{l}0.5 \rightarrow 1 \rightarrow 2 \mathrm{mg} \\
0.5 \rightarrow 1 \rightarrow 2 \rightarrow 4 \mathrm{mg}\end{array}$ & 34 or 58 weeks & 326 \\
\hline
\end{tabular}


serum uric acid level of $\leq 6.0 \mathrm{mg} / \mathrm{dL}$ at 34 and 58 weeks were evaluated in each group. In the analysis of eGFR, paired $t$ tests were conducted to evaluate significant changes between the baseline values and values after the dose period.

\section{Statistical analysis}

Statistical analyses were conducted using JMP10 software (SAS Institute, Cary, NC, USA). Summary statistics and 95\% confidence interval (CI) were calculated. In addition, a paired $t$ test was conducted in the analysis of eGFR, where the significance level was set at 0.05 , in a two-tailed test $(p<0.05)$.

\section{Results}

\section{Pooled analysis of the four clinical trials}

Pooled patient data were divided into four groups (G1-G3b) according to the stage of renal dysfunction. The background information of patients is presented in Table 2. The total number of analyzed cases was 421 . There were no differences between the stages, except in age.

The dose period of dotinurad was 8-14 weeks in the trials. Serum uric acid levels at baseline and after the dose period, the changes from baseline levels, and their ratio (\%) were summarized for each stage (Table 3 ). In each stage, the outcomes were summarized in each dose sub-group (0.5-4 mg) (Table 4).

The outcomes in all stages were as follows. When dotinurad $(0.5 \mathrm{mg})$ was administered, the percentage change in serum uric acid levels from the baseline was $21.81 \% \pm 11.35 \%$, and the percentage of patients achieving serum uric acid levels $\leq 6.0 \mathrm{mg} / \mathrm{dL}$ was $23.1 \%$. When $1 \mathrm{mg}$ was administered, these outcomes were $34.84 \% \pm 9.59 \%$ and $68.9 \%$, when $2 \mathrm{mg}$ was administered, they were $44.23 \% \pm 12.09 \%$ and $84.2 \%$, and when $4 \mathrm{mg}$ was administered, the outcomes were $62.22 \% \pm 8.48 \%$ and $98.4 \%$, respectively. As described above, both outcomes improved with the dosage of dotinurad. Dose dependency was found

Table 2 Patient background information of the combined analysis (4 trials)

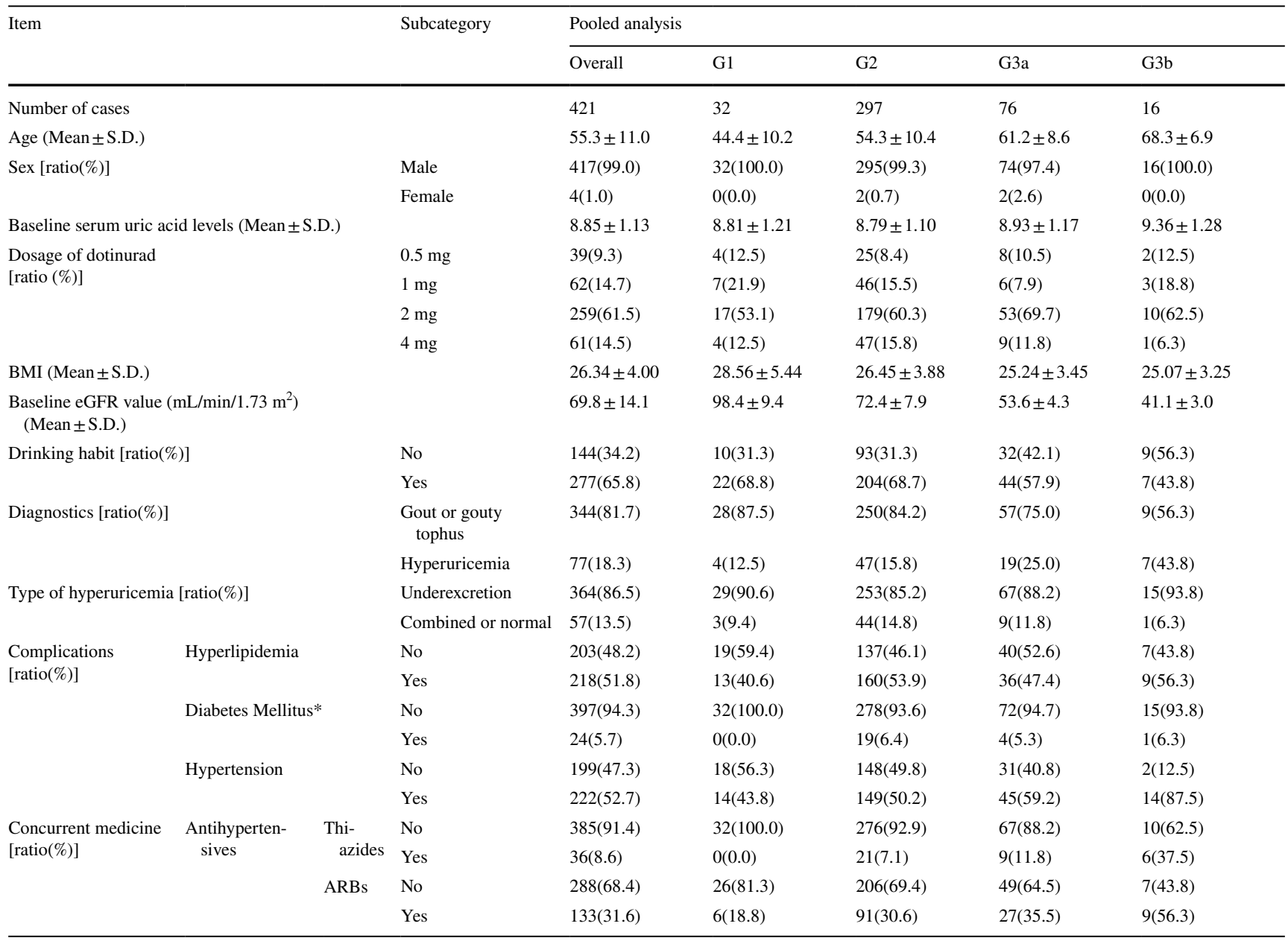

* One case was Type 1. Other cases were Type 2 diabetes 
Table 3 Outcomes of the pooled analysis in each stage

\begin{tabular}{|c|c|c|c|c|c|c|c|c|c|}
\hline Stages & $\begin{array}{l}\text { Cases (at } \\
\text { the base- } \\
\text { line) }\end{array}$ & $\begin{array}{l}\text { Baseline } \\
\text { serum uric } \\
\text { acid level } \\
(\mathrm{mg} / \mathrm{dL})\end{array}$ & $\begin{array}{l}\text { Cases (after } \\
\text { the dose } \\
\text { period) }\end{array}$ & $\begin{array}{l}\text { Serum uric } \\
\text { acid levels } \\
\text { after the dose } \\
\text { period (mg/ } \\
\text { dL) }\end{array}$ & $\begin{array}{l}\text { Changes from } \\
\text { the baseline } \\
(\%)\end{array}$ & $95 \%$ CI & $\begin{array}{l}\text { Changes from } \\
\text { the baseline } \\
(\mathrm{mg} / \mathrm{dL})\end{array}$ & $95 \%$ CI & $\begin{array}{l}\text { Percentage } \\
\text { of patients } \\
\text { achieving a } \\
\text { serum uric } \\
\text { acid level } \\
\text { of } \leq 6.0 \mathrm{mg} / \\
\mathrm{dL}(\%)\end{array}$ \\
\hline Overall & 421 & $8.85 \pm 1.13$ & 420 & $5.00 \pm 1.47$ & $43.40 \pm 15.20$ & $41.94-44.85$ & $-3.85 \pm 1.46$ & $\begin{array}{l}-3.99 \\
\text { to }-3.71\end{array}$ & 78.3 \\
\hline G1 & 32 & $8.88 \pm 1.21$ & 32 & $5.49 \pm 1.51$ & $37.18 \pm 17.68$ & $31.06-43.31$ & $-3.39 \pm 1.92$ & $\begin{array}{l}-4.05 \\
\text { to }-2.72\end{array}$ & 68.8 \\
\hline G2 & 297 & $8.79 \pm 1.10$ & 296 & $4.88 \pm 1.41$ & $44.52 \pm 14.46$ & $42.87-46.17$ & $-3.92 \pm 1.37$ & $\begin{array}{l}-4.07 \\
\text { to }-3.76\end{array}$ & 82.4 \\
\hline G3a & 76 & $8.93 \pm 1.17$ & 76 & $5.14 \pm 1.67$ & $42.63 \pm 16.56$ & $38.91-46.35$ & $-3.79 \pm 1.56$ & $\begin{array}{l}-4.14 \\
\text { to }-3.44\end{array}$ & 68.4 \\
\hline G3b & 16 & $9.36 \pm 1.28$ & 16 & $5.65 \pm 1.06$ & $38.66 \pm 13.85$ & $31.88-45.45$ & $-3.71 \pm 1.59$ & $\begin{array}{l}-4.49 \\
\text { to }-2.93\end{array}$ & 68.8 \\
\hline
\end{tabular}

Mean \pm S.D

to be the same in each stage, and sufficient outcomes were observed when a dose of $2 \mathrm{mg}$ or higher was administered in all stages. In stages G2-G3b, when the renal function of patients is impaired, the percentage of patients achieving the serum uric acid levels $\leq 6.0 \mathrm{mg} / \mathrm{dL}$ was $88.8 \%$ in the $\mathrm{G} 2$ stage, $75.5 \%$ in the G3a stage, and $80.0 \%$ in the G3b stage when $2 \mathrm{mg}$ dotinurad was administered. When $4 \mathrm{mg}$ was administered, the outcome was further improved to $97.9 \%$ in $\mathrm{G} 2,100 \%$ in G3a, and $100 \%$ in G3b. These data indicate the efficacy of dotinurad in patients with mild-to-moderate renal dysfunction.

\section{Long-term analysis}

Patient background information at baseline in stages G1-G3b and the whole population is summarized in Table 5. The number of analyzed cases was 319 , which comprised 24 stage G1 patients, 225 stage G2 patients, 61 stage G3a patients, and 9 stage G3b patients. Similar to the results of the pooled analysis, no differences were found between the stages, except in age.

The patient outcomes obtained from the safety analysis using the safety population (SP), including AEs at each stage, are shown in Table 6. There were no differences in the incidence of AEs (\%) among the four stages. A serious adverse reaction (ADR) was stage I gastric cancer observed in stage G1.

Serum uric acid levels at baseline and after the dose period, changes from baseline, and percentage changes in each stage are shown in Table 7. The outcomes in the dose of each stage are shown in Table 8.

The outcomes of the whole population were as follows: in 276 cases that were administered $2 \mathrm{mg}$ dotinurad for 34 or 58 weeks, the percentage change in serum uric acid level from baseline was $47.52 \% \pm 11.99 \%$, and the percentage of patients achieving a serum uric acid level $\leq 6.0 \mathrm{mg} /$ $\mathrm{dL}$ was $89.9 \%$. In 43 cases that were administered $4 \mathrm{mg}$ dotinurad, these outcomes were $54.88 \% \pm 9.49 \%$ and $90.6 \%$, respectively.

The outcomes of different renal dysfunction stages (G1-G3b) were as follows: in stage G1, the percentage change in the serum uric acid level from baseline was $48.81 \% \pm 15.68 \%$, and the percentage of patients achieving a serum uric acid level $\leq 6.0 \mathrm{mg} / \mathrm{dL}$ was $85.0 \%$ when $2 \mathrm{mg}$ dotinurad was administered. When $4 \mathrm{mg}$ was administered, the outcomes were $47.29 \% \pm 13.01 \%$ and $100.0 \%$, respectively. In stage $\mathrm{G} 2$, the outcomes were $47.69 \% \pm 12.34 \%$ and $90.7 \%$ in the $2 \mathrm{mg}$ sub-group and $56.25 \% \pm 8.47 \%$ and $100.0 \%$ in the $4 \mathrm{mg}$ sub-group, respectively. In stage G3a, the outcomes were $46.73 \% \pm 9.64 \%$ and $91.2 \%$ in the $2 \mathrm{mg}$ sub-group and $55.36 \% \pm 12.24 \%$ and $75.0 \%$ in the $4 \mathrm{mg}$ sub-group, respectively. In stage $\mathrm{G} 3 \mathrm{~b}$, the outcomes were $44.85 \% \pm 6.66 \%$ and $60.0 \%$ in the $2 \mathrm{mg}$ sub-group and $51.38 \% \pm 10.62 \%$ and $75.0 \%$ in the $4 \mathrm{mg}$ sub-group, respectively. In stage $\mathrm{G} 3 \mathrm{~b}$, the percentage of patients achieving a serum uric acid level of $\leq 6.0 \mathrm{mg} / \mathrm{dL}$ was relatively low. However, this can be attributed to the relatively high serum uric acid level at baseline, and large variations due to the 


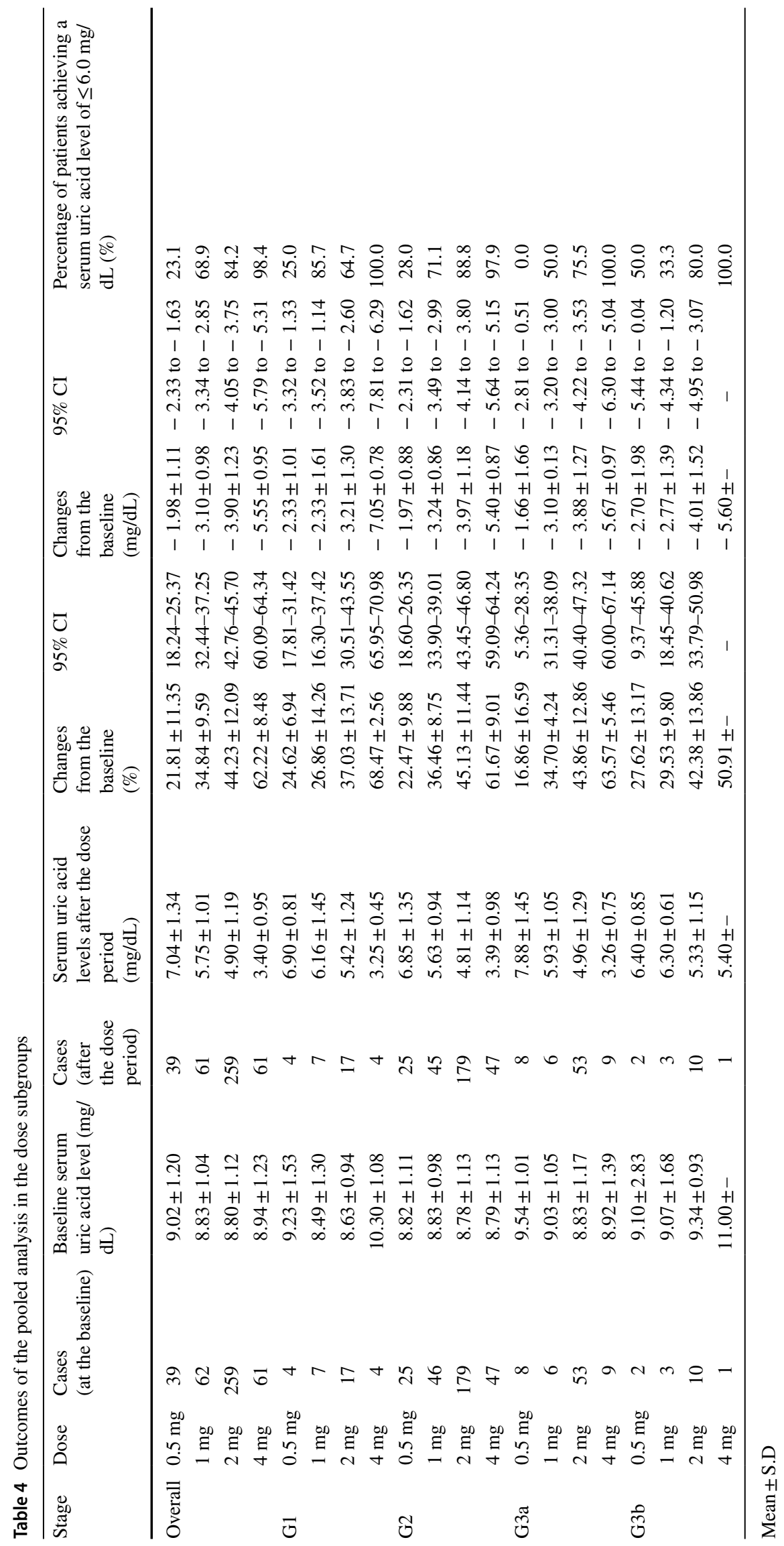


Table 5 Patient background information of long-term analysis

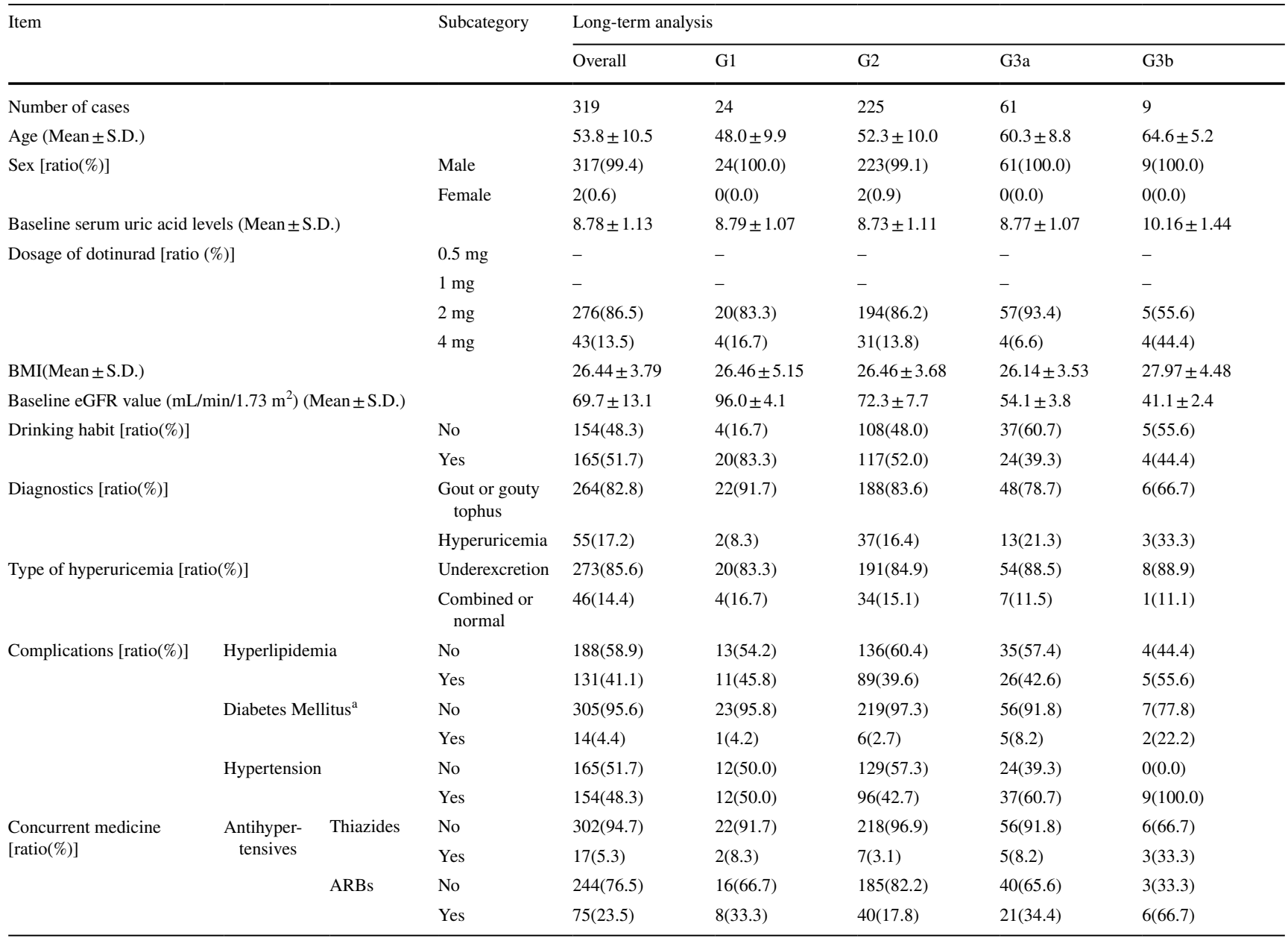

${ }^{\mathrm{a}}$ All of them were Type 2 diabetes

Table 6 Adverse reactions

\begin{tabular}{|c|c|c|c|c|c|c|c|c|}
\hline \multirow{3}{*}{$\begin{array}{l}\text { Stages } \\
\text { Number of cases }\end{array}$} & \multirow{2}{*}{\multicolumn{2}{|c|}{$\frac{\mathrm{G} 1}{24}$}} & \multirow{2}{*}{\multicolumn{2}{|c|}{$\frac{\mathrm{G} 2}{225}$}} & \multirow{2}{*}{\multicolumn{2}{|c|}{$\frac{\mathrm{G} 3 \mathrm{a}^{\mathrm{a}}}{62}$}} & \multirow{2}{*}{\multicolumn{2}{|c|}{$\frac{\mathrm{G} 3 \mathrm{~b}}{9}$}} \\
\hline & & & & & & & & \\
\hline & $\begin{array}{l}\text { Num- } \\
\text { ber of } \\
\text { patients }\end{array}$ & Incidence $(\%)$ & $\begin{array}{l}\text { Num- } \\
\text { ber of } \\
\text { patients }\end{array}$ & Incidence $(\%)$ & $\begin{array}{l}\text { Num- } \\
\text { ber of } \\
\text { patients }\end{array}$ & Incidence $(\%)$ & $\begin{array}{l}\text { Num- } \\
\text { ber of } \\
\text { patients }\end{array}$ & Incidence $(\%)$ \\
\hline AEs & 15 & $(62.5)$ & 148 & $(65.8)$ & 40 & $(64.5)$ & 6 & (66.7) \\
\hline Adverse reactions (ADRs) & 4 & $(16.7)$ & 50 & $(22.2)$ & 12 & $(19.4)$ & 1 & $(11.1)$ \\
\hline Serious AEs & 1 & $(4.2)$ & 5 & $(2.2)$ & 3 & $(4.8)$ & 0 & $(0.0)$ \\
\hline Serious ADRs & 1 & $(4.2)$ & 0 & $(0.0)$ & 0 & $(0.0)$ & 0 & $(0.0)$ \\
\hline AEs leading to death & 0 & $(0.0)$ & 0 & $(0.0)$ & 0 & $(0.0)$ & 0 & $(0.0)$ \\
\hline ADRs leading to death & 0 & $(0.0)$ & 0 & $(0.0)$ & 0 & $(0.0)$ & 0 & $(0.0)$ \\
\hline AEs leading to discontinuation & 0 & $(0.0)$ & 9 & $(4.0)$ & 2 & $(3.2)$ & 0 & $(0.0)$ \\
\hline ADRs leading to discontinuation & 0 & $(0.0)$ & 5 & $(2.2)$ & 1 & $(1.6)$ & 0 & $(0.0)$ \\
\hline
\end{tabular}

AEs leading to discontinuation in stage G2: urinary bladder cancer, nephrolithiasis (4 cases), uncontrolled diabetes mellitus, eczema, acute inflammation of gall bladder, diverticulitis. ADRs leading to discontinuation in stage G2: nephrolithiasis (4 cases), eczema. AEs leading to discontinuation in stage G3a: gastrointestinal stomal tumor, nephrolithiasis. ADRs leading to discontinuation in stage G3a: nephrolithiasis

*The number of AEs contained those of ADRs in the same stage

${ }^{a}$ Because this analysis used the Safety Population (SP), the number of stage G3a was 62, which was larger than other tables by 1 case 
Table 7 Outcomes of the long-term analysis in each stage

\begin{tabular}{|c|c|c|c|c|c|c|c|c|c|}
\hline Stage & $\begin{array}{l}\text { Cases } \\
\text { (at the base- } \\
\text { line) }\end{array}$ & $\begin{array}{l}\text { Baseline } \\
\text { serum uric } \\
\text { acid level } \\
(\mathrm{mg} / \mathrm{dL})\end{array}$ & $\begin{array}{l}\text { Cases } \\
\text { (after } \\
\text { the dose } \\
\text { period) }\end{array}$ & $\begin{array}{l}\text { Serum uric } \\
\text { acid levels } \\
\text { after the dose } \\
\text { period } \\
(\mathrm{mg} / \mathrm{dL})\end{array}$ & $\begin{array}{l}\text { Changes from } \\
\text { the baseline } \\
(\%)\end{array}$ & $95 \%$ CI & $\begin{array}{l}\text { Changes from } \\
\text { the baseline } \\
(\mathrm{mg} / \mathrm{dL})\end{array}$ & $95 \%$ CI & $\begin{array}{l}\text { Percentage } \\
\text { of patients } \\
\text { achieving a } \\
\text { serum uric } \\
\text { acid level } \\
\text { of } \leq 6.0 \mathrm{mg} / \\
\mathrm{dL}(\%)\end{array}$ \\
\hline Overall & 319 & $8.78 \pm 1.13$ & 319 & $4.51 \pm 1.15$ & $48.51 \pm 11.94$ & $47.20-49.82$ & $-4.27 \pm 1.23$ & $\begin{array}{l}-4.41 \\
\text { to }-4.14\end{array}$ & 90.6 \\
\hline G1 & 24 & $8.79 \pm 1.07$ & 24 & $4.47 \pm 1.23$ & $48.56 \pm 15.02$ & $42.55-54.56$ & $-4.32 \pm 1.58$ & $\begin{array}{l}-4.95 \\
\text { to }-3.69\end{array}$ & 87.5 \\
\hline G2 & 225 & $8.73 \pm 1.11$ & 225 & $4.46 \pm 1.17$ & $48.87 \pm 12.23$ & $47.27-50.46$ & $-4.28 \pm 1.24$ & $\begin{array}{l}-4.44 \\
\text { to }-4.11\end{array}$ & 92.0 \\
\hline G3a & 61 & $8.77 \pm 1.07$ & 61 & $4.63 \pm 1.05$ & $47.30 \pm 9.95$ & $44.80-49.80$ & $-4.15 \pm 0.99$ & $\begin{array}{l}-4.39 \\
\text { to }-3.90\end{array}$ & 90.2 \\
\hline G3b & 9 & $10.16 \pm 1.44$ & 9 & $5.28 \pm 1.02$ & $47.75 \pm 8.74$ & $42.04-53.46$ & $-4.88 \pm 1.27$ & $\begin{array}{l}-5.71 \\
\text { to }-4.05\end{array}$ & 66.7 \\
\hline
\end{tabular}

Mean \pm S.D

small number of cases, as the change in uric acid level from baseline was the same as that observed in other stages.

The eGFR values at baseline and after the dose period are shown in Table 9 and Appendix Table 10.

The dose period for this analysis was 34 or 58 weeks. A total of 299 patients were examined after 34 weeks, and 105 patients who participated early period in the study were observed to have completed 58 weeks of intervention. The baseline eGFR value in stage G1 was $96.0 \pm 4.1 \mathrm{~mL} /$ $\mathrm{min} / 1.73 \mathrm{~m}^{2}$ and $93.6 \pm 8.2 \mathrm{~mL} / \mathrm{min} / 1.73 \mathrm{~m}^{2}$ after 34 weeks, $93.1 \pm 12.2 \mathrm{~mL} / \mathrm{min} / 1.73 \mathrm{~m}^{2}$ after 58 weeks. In stage $\mathrm{G} 2$, the baseline values were $72.3 \pm 7.7 \mathrm{~mL} /$ $\mathrm{min} / 1.73 \mathrm{~m}^{2}, 73.0 \pm 9.4 \mathrm{~mL} / \mathrm{min} / 1.73 \mathrm{~m}^{2}$ after 34 weeks, and $70.4 \pm 10.5 \mathrm{~mL} / \mathrm{min} / 1.73 \mathrm{~m}^{2}$ after 58 weeks. In stage $\mathrm{G} 3 \mathrm{a}$, the baseline values were $54.1 \pm 3.8 \mathrm{~mL} / \mathrm{min} / 1.73 \mathrm{~m}^{2}$, $55.2 \pm 6.2 \mathrm{~mL} / \mathrm{min} / 1.73 \mathrm{~m}^{2}$ after 34 weeks, $53.4 \pm 6.1 \mathrm{~mL} /$ $\min / 1.73 \mathrm{~m}^{2}$ after 58 weeks. In stage G3b, the baseline values were $41.1 \pm 2.4 \mathrm{~mL} / \mathrm{min} / 1.73 \mathrm{~m}^{2}, 40.7 \pm 4.7 \mathrm{~mL} /$ $\mathrm{min} / 1.73 \mathrm{~m}^{2}$ after 34 weeks, and $40.0 \pm 1.4 \mathrm{~mL} / \mathrm{min} / 1.73 \mathrm{~m}^{2}$ after 58 weeks. The results of the paired $t$ test ( $p$ values are shown in Table 9), a significant change was observed in stage $\mathrm{G} 2$ after 34 weeks of treatment $(p=0.049)$. However, no significant change was observed after 58 weeks in the same stage or in other stages between the baseline values and values after the dose period. In stages G3a and $\mathrm{G} 3 \mathrm{~b}$, when the renal function of the patients is impaired, the eGFR values remained unchanged throughout the dose period (Appendix Table 10).

\section{Discussion}

Changes in serum uric acid levels from baseline in stages G1-G3b are summarized in Tables 3 and 7. When dotinurad was administered for 8-14 weeks, changes in serum uric acid levels from baseline were similar between the four stages. Even in stages G3a and G3b, the efficacy of dotinurad was similar to that of the other stages. Based on this result, it was confirmed that dotinurad monotherapy is expected to have sufficient uric acid-lowering effects in patients with impaired renal function. As the serum uric acid level-lowering effect of dotinurad is dose dependent, the serum uric acid levels after the dose period observed in the pooled analysis (including patient groups administered 0.5 or $1 \mathrm{mg}$ dotinurad) were higher than those observed in the long-term analysis.

In the long-term analysis, in which 2 or $4 \mathrm{mg}$ dotinurad was administered during the maintenance period, the changes in the serum uric acid levels from baseline were similar in all stages. In addition, the percentage of patients achieving a serum uric acid level of $\leq 6.0 \mathrm{mg} / \mathrm{dL}$ was approximately $90 \%$ in stages G1, G2, and G3a. In these stages, dotinurad is expected to have a satisfactory effect. In stage G3b, although the changes in the serum uric acid level from baseline were higher than those in the other stages, the percentage of patients achieving a serum uric acid level of $\leq 6.0 \mathrm{mg} / \mathrm{dL}$ was only approximately $67 \%$. This was thought to be due to the relatively higher 

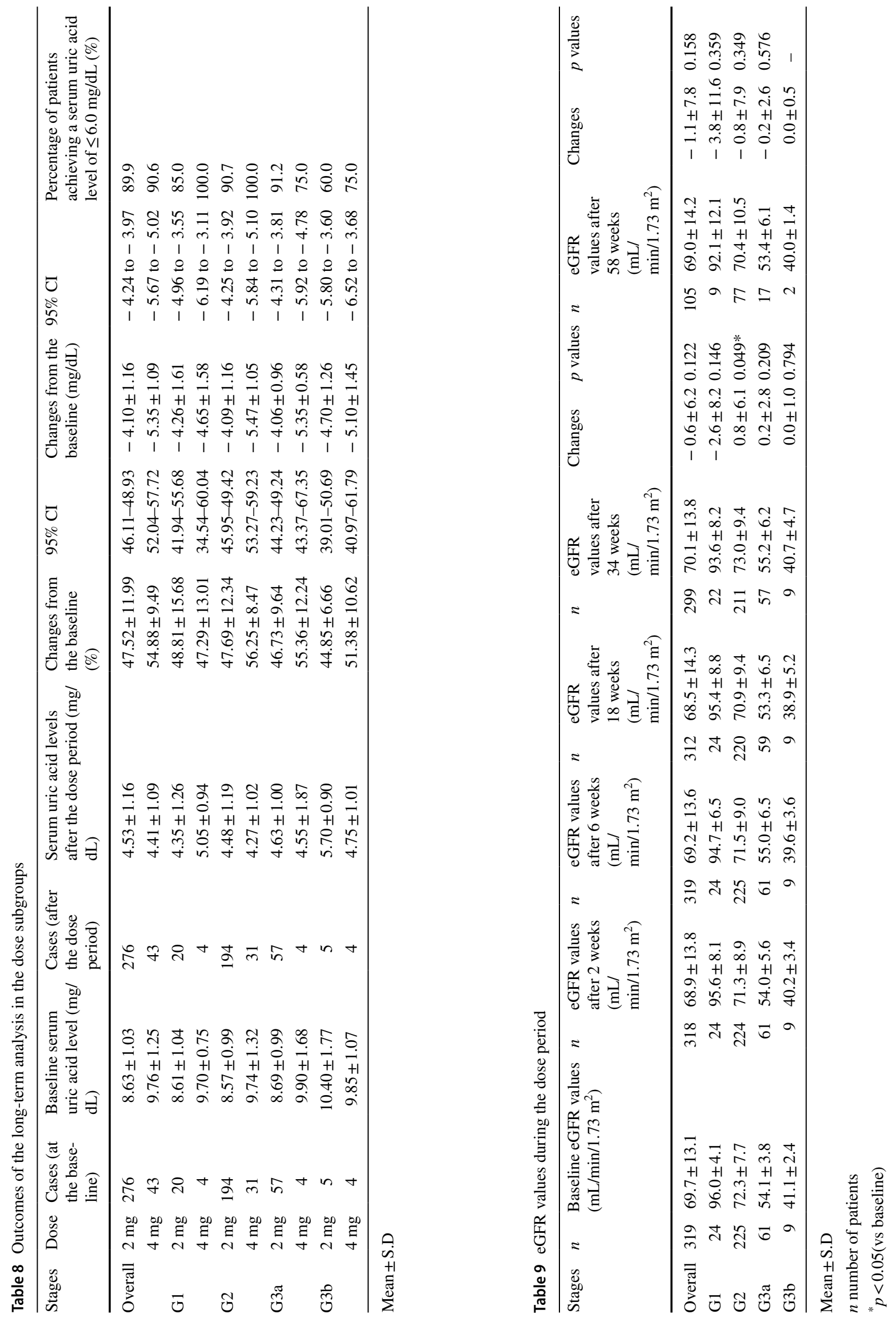
baseline serum uric acid level in this stage. With regard to safety in long-term use, the risks of AEs were similar in all stages, and no particular risk was observed in patient groups with an impaired renal function. Although a significant change in the eGFR value was observed after 34 weeks in stage G2, it was difficult to identify the clinical importance of this change, because no significant change was observed after 58 weeks in the same group. Overall, the eGFR was stable during the dose period in all stages, and no aggravation was observed (Table 9; Appendix Table 10).

Dotinurad monotherapy showed a satisfactory effect in the treatment of patients with hyperuricemia whose eGFR values were $30 \mathrm{~mL} / \mathrm{min} / 1.73 \mathrm{~m}^{2}$ or higher, and efficacy and safety were similar in different stages of renal dysfunction. In addition, a decline in the eGFR was not observed during the dose period. From the perspective of the eGFR, there was no increase in the renal load during treatment with dotinurad.

On the contrary, in a study using lesinurad, an SURI that has been approved in the USA and EU, elevations in the serum creatinine levels and an increased risk of renal dysfunction were observed in patients receiving high-dose treatments (400 mg) [7]. Further research, focusing on mechanism and dose dependency, is essential to clarify the relationship between SURI and renal load. As this study was a pooled analysis of multiple trials, there was a large variation in the number of cases in the study groups. Therefore, heterogeneity bias cannot be excluded, and the statistical reliability is limited. The outcomes of stage G3b should be evaluated carefully, because the sample size was small in this group. To gain a better understanding, prospective clinical intervention studies in patients with CKD are desirable in the future.

\section{Conclusions}

In Japan, the number of patients with renal impairment is expected to increase due to the growing incidence of lifestyle-related diseases. This study proved that dotinurad could be an effective treatment option for hyperuricemia in such populations.

\section{Appendix}

See Table 10.

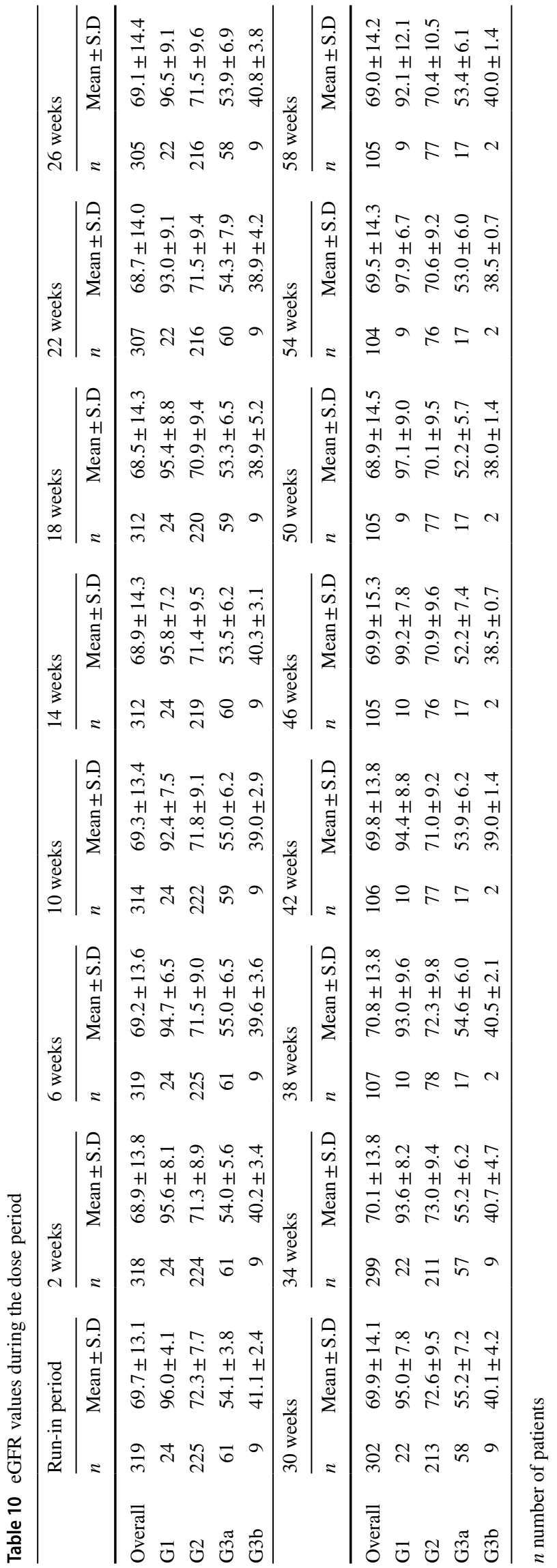




\section{Declarations}

Conflict of interest TH was an advisor to Fuji Yakuhin Co., Ltd. regarding these studies and received manuscript fees. TT is an employee of Mochida Pharmaceutical Co. Ltd. TB is an employee of Fuji Yakuhin Co., Ltd.

Research involving human participants and/or Animals/Informed consent Not applicable. This was an analytical study that used anonymized data in a data set without any personal information.

Open Access This article is licensed under a Creative Commons Attribution 4.0 International License, which permits use, sharing, adaptation, distribution and reproduction in any medium or format, as long as you give appropriate credit to the original author(s) and the source, provide a link to the Creative Commons licence, and indicate if changes were made. The images or other third party material in this article are included in the article's Creative Commons licence, unless indicated otherwise in a credit line to the material. If material is not included in the article's Creative Commons licence and your intended use is not permitted by statutory regulation or exceeds the permitted use, you will need to obtain permission directly from the copyright holder. To view a copy of this licence, visit http://creativecommons.org/licenses/by/4.0/.

\section{References}

1. Japanese Society of Gout and Uric and Nucleic Acids. Guideline for the management of hyperuricemia and gout. 3rd ed. Tokyo: Shindan To Chiryo Sha. 2018. p. 72, 115 (In Japanese)

2. Toda A, Ishizaka Y, Tani M, Yamakado M. Hyperuricemia is a significant risk factor for the onset of chronic kidney disease. Nephron Clin Pract. 2014;126:33-8.

3. Kuwabara M, Niwa K, Nishi Y, Mizuno A, Asano T, et al. Relationship between serum uric acid levels and hypertension among Japanese individuals not treated for hyperuricemia and hypertension. Hypertens Res. 2014;37:785-9.

4. Hakoda M, Kasagi F. Future trends for the number of gout patients in Japan. Gout Nucleic Acid Metab. 2020;44:33-9.

5. Hosoya T, Kamatani N, Taniguchi A. The use survey of antihyperuricemic in clinicians. Gout Nucleic Acid Metab. 2018;42:23-9 (In Japanese).
6. Miner JN, Tan PK, Hyndman D, Liu S, Iverson C, et al. Lesinurad, a novel, oral compound for gout, acts to decrease serum uric acid through inhibition of urate transporters in the kidney. Arthritis Res Ther. 2016;18:214

7. Tausche AK, Alten R, Dalbeth N, Kopicko J, Fung M, et al. Lesinurad monotherapy in gout patients intolerant to a xanthine oxidase inhibitor: a 6-month phase 3 clinical trial and extension study. Rheumatology. 2017;56:2170-8.

8. Hosoya T, Sano T, Sasaki T, Fushimi M, Ohashi T. Dotinurad versus benzbromarone in Japanese hyperuricemic patients with or without gout: a randomized, double-blind, parallel-group, phase 3 study. Clin Exp Nephrol. 2020;24(Suppl 1):S62-70.

9. Hosoya T, Furuno K, Kanda S. A non-inferiority study of the novel selective urate reabsorption inhibitor dotinurad versus febuxostat in hyperuricemic patients with or without gout. Clin Exp Nephrol. 2020;24(Suppl 1):S71-9.

10. Hosoya T, Fushimi M, Okui D, Sasaki T, Ohashi T. Open-label study of long-term administration of dotinurad in Japanese hyperuricemic patients with or without gout. Clin Exp Nephrol. 2020;24(Suppl 1):S80-91.

11. Nitta K, Masakane I, Hanafusa N, Taniguchi M, Hasegawa T, et al. Annual dialysis data report 2017: JSDT renal data registry. Ren Replace Ther. 2019;5:2-44.

12. Hosoya T, Sano T, Sasaki T, Fushimi M, Ohashi T, et al. Clinical efficacy and safety of dotinurad, a novel selective urate reabsorption inhibitor, in Japanese hyperuricemic patients with or without gout: an exploratory, randomized, multicenter, double-blind, placebo-controlled, parallel-group early phase 2 study. Clin Exp Nephrol. 2020;24(Suppl 1):S44-52.

13. Hosoya T, Sano T, Sasaki T, Fushimi M, Ohashi T. Clinical efficacy and safety of dotinurad, a novel selective urate reabsorption inhibitor, in Japanese hyperuricemic patients with or without gout: randomized, multicenter, double-blind, placebo-controlled, parallel-group, confirmatory phase 2 study. Clin Exp Nephrol. 2020;24(Suppl 1):S53-61.

14. Japanese Society of Nephrology. Evidence-based clinical practice guideline for chronic kidney disease. Tokyo-Igakusha. 2018. p. 3 (In Japanese).

Publisher's Note Springer Nature remains neutral with regard to jurisdictional claims in published maps and institutional affiliations. 